EESTI NSV TEADUSTE AKADEEMIA TOIMETISED. 23. KOIDE KEEMIA * GEOLOOGIA. 1974, NR. 3

ИЗВЕСТИЯ АКАДЕМИИ НАУК ЭСТОНСКОИ ССР. ТОМ 23 ХИМИЯ * ГЕОЛОГИЯ. 1974, Nㅛ 3

УдК $551.7: 540.3$

\title{
О РАСПРЕДЕЛЕНИИ МИКРОЭЛЕМЕНТОВ И ГЕНЕЗИСЕ СУЛЬФИДНОЙ МИНЕРАЛИЗАЦИИ В КРИСТАЛЛИЧЕСКИХ ПОРОДАХ ЯГАЛАСКОЙ ТОЛЩИ
}

В метаморфизованных и мигматизированных первично-осадочно-вулканогенных породах ягалаской толщи широко распространена сульфидная минерализация (Петерселль, 1974). Она представлена сингенетической вкрапленностью и ее перекристаллизованными и переотложенными в процессах метаморфизма разновидностями первой стадии, а также секущими прожилками второй стадии. Сульфидная минерализация образована пирротином, пиритом, реже халькопиритом, сфалеритом, редко галенитом, молибденитом, марказитом и другими минералами и обычно сопровождается аномальными содержаниями в породе $\mathrm{Co}, \mathrm{Ni}$, $\mathrm{Cu}, \mathrm{Pb}, \mathrm{Zn}, \mathrm{Mo}, \mathrm{F}, \mathrm{Au}$ и других элементов.

Фоновые содержания микроэлементов в разновидностях пород ягалаской толщи близки к кларковым (Кивисилла и др., 1974, табл. 1). В них нередко преобладает свойственная для спилит-кератофировой формации ассоциация элементов. В первично-вулканогенных породах толщи выделяются более основные разновидности - биотит-амфиболовые гнейсы - с аномальным содержанием и дисперсией $\mathrm{Cr}, \mathrm{Co}, \mathrm{Ni}, \mathrm{Cu}$ и других элементов, а также более кислые разновидности - кварцполевошпатовые, биотитовые и частично амфибол-биотитовые гнейсы с аномальным содержанием $\mathrm{Cu}, \mathrm{Mo}, \mathrm{Zn}$ и иногда $\mathrm{Au}$,

В более кислых разновидностях пород содержания $\mathrm{Ni}$ и Со становятся фоновыми, а их отношение уменьшается. Аномальные содержания микроэлементов в основном приурочены к отдельным пластам или участкам гнейсов, в которых нередко наблюдается сингенетическая вкрапленность сульфидов или ее перекристаллизованные и переотложенные разновидности. Аномальные содержания $\mathrm{Ni}, \mathrm{Co}, \mathrm{Mo}$ и других элементов не всегда сопровождаются вкрапленностью сульфидов. В ряде случаев эти аномалии, в первую очередь $\mathrm{Cr}$, Ni и $\mathrm{Co}$, вызваны прослоями более основных пород, но в некоторых скважинах аномальное содержание $\mathrm{Ni}$, Мо и других элементов нельзя объяснить изменчивостью кислотности пород. Как показали анализы мономинеральных фракций биотитов из пород таких скважин, большая часть рудных элементов сконцентрирована здесь именно в биотитах.

Слои вулканогенных пород, в которых геохимические аномалии $\mathrm{Ni}$, $\mathrm{Cu}, \mathrm{Zn}, \mathrm{Mo}$, реже $\mathrm{Co}, \mathrm{Pb}$ и $\mathrm{Au}$ сопровождаются явной сингенетической вкрапленностью сульфидов или концентрацией их в биотите, как правило, не отличаются гидротермальными или другими изменениями пород, свидетельствующими о наложенном характере минерализации. Содержание микроэлементов в пирротине и пирите из этих пород приведено в табл. 1, откуда видно, что различия содержаний микроэлементов в 
Ф-110 Пирротин из мелкозернистых
графитсодер жащих гнейсов Пирротин из миг. матизированных жащих гнейсов

"ирротин из био. тит-амфиболевых гнейсов

Пирротин̈ из мигматизированных глиноземистых гнейcoв

Пирит из мигма глиноземнстых гнейсов

Пирит из амфи -

Пирит из пегматов

Пирнт из глиносов бол-бнотитовых

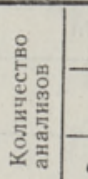

\begin{tabular}{|c|c|c|c|c|c|c|c|}
\hline \multicolumn{2}{|c|}{$\mathrm{Ni}$} & \multicolumn{3}{|c|}{ Co } & \multicolumn{3}{|c|}{$\mathrm{Cu}$} \\
\hline до & $\tilde{x}$ & OT & до & $\tilde{x}$ & от & до & $\tilde{\tilde{x}}$ \\
\hline
\end{tabular}

\begin{tabular}{|l|l|l|}
\hline \multicolumn{3}{|c|}{$\mathrm{Pb}$} \\
\hline от & до & $\tilde{x}$ \\
\hline
\end{tabular}

Сингенетическая I генерация

Сингенетическая вкрапленность
II генерации

Сннгенетическая вкрапленность
И II генераций

". қи руе прожилрации

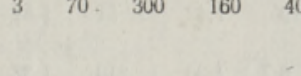

$\begin{array}{lllll}49 & 80 & 100 & 86 & 0\end{array}$

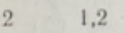

от

\begin{tabular}{l|l}
$\mathrm{Zn}$ \\
\hline
\end{tabular}

\begin{tabular}{|l|l|l|}
\hline \multicolumn{3}{|c|}{$\mathrm{Ag}$} \\
\hline от & до & $\tilde{x}$ \\
\hline
\end{tabular}

\begin{tabular}{|l|l|l|}
\multicolumn{3}{|c|}{ As } \\
\hline от & до & $\tilde{x}$
\end{tabular}

\begin{tabular}{|c|c|c|}
\multicolumn{3}{|c|}{$\mathrm{Cr}$} \\
\hline от & до & $\tilde{x}$
\end{tabular}

Секущие прожнл$\begin{array}{rrr}\text { ки и } & \text { вкраплен- } \\ \text { ность } & \text { рудной }\end{array}$ генерацин

$\begin{array}{lllllllllll}2 & 50 & 500 & 160 & 40 & 50 & 45 & 200 & 400 & 280 & 0.1\end{array}$

$20 \quad 0,56$

$60 \quad 200$

$130 \quad 0,5$

$30-$

200

3,3

$$
\text { ". }
$$

$\begin{array}{llllllllll}40 & 40 & 40 & 10 & 10 & 10 & 40 & 200 & 89\end{array}$

$0,8 \quad 0,28$

100800

$240 \quad 0,6$

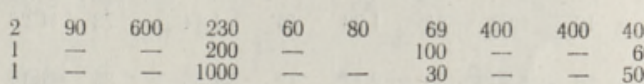

$\begin{array}{ll}0,1 & 0.1\end{array}$

$80 \quad 100$

$89 \quad 0,5 \quad 1$

$0.71 \quad 30$

- -

400

$\begin{array}{ll}66 & 8,8\end{array}$

Секущие прожил-

генерации

П римеч ание. Анализы выполнены в лабораторни тпи на спектрографе ДФС-8 ответственным аналитиком Хельви Хёдреярв. 


\begin{tabular}{|c|c|c|c|c|c|c|c|c|c|c|c|c|c|c|c|c|}
\hline \multirow[b]{2}{*}{ Породы } & \multirow{2}{*}{$\begin{array}{l}\text { Номера } \\
\text { скважин }\end{array}$} & \multirow{2}{*}{ 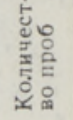 } & \multicolumn{2}{|c|}{$\mathrm{Cr}$} & \multicolumn{2}{|c|}{ Co } & \multicolumn{2}{|c|}{$\mathrm{Ni}$} & \multicolumn{2}{|c|}{$\mathrm{Cu}$} & \multicolumn{2}{|c|}{$\mathrm{Pb}$} & \multicolumn{2}{|c|}{$\mathrm{Zn}$} & \multicolumn{2}{|c|}{ Mo } \\
\hline & & & $\tilde{x}$ & $\varepsilon$ & $\tilde{x}$ & $="$ & $\tilde{x}$ & $\varepsilon$ & $\tilde{x}$ & $\varepsilon$ & $\tilde{x}$ & $\varepsilon$ & $\tilde{x}$ & $e$ & $\tilde{x}$ & e \\
\hline
\end{tabular}

А. Первично-вулканогени ые

Гнейс кварц-полевошпатовый от мелкодо среднезернистого

\begin{tabular}{|c|c|c|c|c|c|c|c|c|c|c|c|c|c|c|c|}
\hline Ф-111 & 79 & 13 & 1,31 & - & - & - & - & 13 & 1.62 & 19 & 1,42 & 51 & 1,51 & 3,3 & 2.55 \\
\hline Ф-104 & 23 & 39 & 1.29 & 11 & 1.17 & $\sim 10$ & - & 12 & 1.67 & 8.7 & 1,30 & 210 & 1,32 & 16 & 3.34 \\
\hline Ф-104 & 29 & 33 & 1,16 & 12 & 1,09 & $\sim 11$ & - & 17 & 1,59 & 10 & 1,74 & 160 & 1,30 & 2,0 & 2,00 \\
\hline Ф-108 & 22 & 18 & 1,39 & 8,8 & 1,36 & 12 & 1,17 & 33 & 2,00 & 8,7 & 1,26 & 86 & 1,28 & $\sim 3$ & - \\
\hline Ф-108 & 30 & 27 & 1,33 & 10 & 1,30 & 13 & 1,23 & 21 & 2,00 & 8,3 & 1.21 & 100 & 1,40 & $\sim_{2}$ & - \\
\hline$\Phi-116$ & 27 & 120 & 3,24 & 9,5 & 1,32 & 16 & 1,93 & 21 & 1,93 & 16 & 1,44 & 73 & 1,26 & - & - \\
\hline Ф-116 & 78 & 420 & 2,45 & 14 & 1,28 & 58 & 1,90 & 23 & 2,17 & 12 & 1,33 & 85 & 1,14 & - & - \\
\hline Ф-116 & 25 & 660 & 2,58 & 20 & 1,40 & 120 & 2,33 & 23 & 1,82 & 13 & 1,31 & 83 & 1,20 & - & - \\
\hline $\begin{array}{l}\Phi-102 \\
\Phi-113\end{array}$ & 86 & 130 & 1,38 & 15 & 1,27 & 28 & 1,46 & 31 & 2,30 & 18 & 1,61 & 190 & 1,31 & - & \\
\hline Ф-110 & 27. & 70 & 2,00 & 11 & 1,36 & 32 & 2,06 & 43 & 1,87 & 16 & 2.62 & 220 & 2,14 & 2,2 & 2,95 \\
\hline$\Phi-110$ & 21 & 91 & 1,41 & 21 & 1,72 & 122 & 1,67 & 105 & 1,29 & 22 & 2,44 & 310 & 1,27 & 17 & 2,96 \\
\hline$\Phi \cdot 110$ & 9 & 73 & 1,39 & 17 & 1,66 & 114 & 1,81 & 88 & 1,38 & 25 & 1,77 & 261 & 1,90 & 16 & 2,52 \\
\hline & 10 & 167 & & 29 & & 101 & & 90 & & 16 & & 93 & & - & \\
\hline & $\underset{12}{2}$ & $\overline{-}$ & & $\begin{array}{l}20 \\
28\end{array}$ & & $\begin{array}{l}100 \\
260\end{array}$ & & $\begin{array}{r}76 \\
150\end{array}$ & & $\begin{array}{l}11 \\
48\end{array}$ & & $\begin{array}{l}220 \\
700\end{array}$ & & $\overline{-}$ & \\
\hline
\end{tabular}
участками с амфиболом

Гнейс амфибол-биотитовый среднезернистый

Гнейс биотитовый среднезернистый

Гнейс амфибол-биотитовый среднезернистый

Гнейс биотитовый от мелко- до среднезернистого

Гнейс амфибол-биотитовый от мелкодо среднезернистого

Гнейс биотит-амфиболовый от мелкодо среднезернистого

Б. Перв и чно-ос а дочные

Гнейс биотитовый мелкозернистый

Гнейс биотитовый, участками графитсодержащий мелкозернистый

Гнейсы графит- и сульфидсодержащие от мелко-до среднезернистых

Гнейсы графит- и сульфидсодержащие, с кордиеритом, снльно мигматизиро-

В. Черные сланды Фенио.

с к а нди и

a) района Куопно (Lonka, 1967)

Лампинсаариского рудного комппр. 90 np. 2100

* Среднеарифметическое содержание. 
пирротинах объясняется в первую очередь неоднородностью первичного состава рудного вещества, а также перераспределением его в процессах метаморфизма. Если сопоставить содержания микроэлементов в этих пирротинах с их содержанием в пирротинах из сингенетических высокометаморфизованных руд и из субвулканических гидротермальных руд (Цамбел и др., 1971), то выясняется, что они занимают промежуточное положение между этими типами пирротинов. Имея в виду сказанное, а также учитывая характер сульфидной минерализации, вполне правдоподобно объяснить, что накопление рудного вещества в вулканогенных породах происходило одновременно с вулканической деятельностью.

Уровень содержаний $\mathrm{Cr}, \mathrm{Co}, \mathrm{Ni}, \mathrm{Cu}, \mathrm{Pb}, \mathrm{Zn}$ и Мо в первично-осадочных гнейсах толщи обычно занимает промежуточное положение между содержанием этих элементов в более основных и в более кислых разновидностях вулканогенных пород. Исключение составляют только графит- и сульфидсодержащие гнейсы, в которых содержание указанных элементов явно аномальное и наиболее близко к содержанию их в глубоководных глинистых осадках (табл. 2). Аналогично породам вулканогенного ряда в осадочных гнейсах выделяются слои и участки с аномальным содержанием элементов, которые в большинстве случаев сопровождаются явной сульфидной вкрапленностью или прожилками.

Содержание и распределение микроэлементов в графит- и сульфидсодержащих разновидностях глиноземистых гнейсов изучены в скважине $Ф-110$ (Ягала). Здесь в темно-серых микро- и мелкозернистых $(0,1-0,5$ мм) гнейсах (табл. 2) количество микроэлементов превышает фоновое в $2-3$ и более раз и приближается к содержанию этих элементов в черных сланцах открытой части Балтийского щита. Повышенные концентрации $\mathrm{Cr}, \mathrm{Co}, \mathrm{Ni}, \mathrm{Cu}, \mathrm{Zn}$ и Мо отмечаются в микро- и мелкозернистых немигматизированных разновидностях пород, т. е. в слоях c развитой сингенетической сульфидной минерализацией первой генерации первой стадии (Петерселль, 1974).

В мигматизированных разновидностях, где преобладает перекристаллизованная и переотложенная сингенетическая сульфидная минерализация, содержание этих элементов несколько ниже, а содержание $\mathrm{Pb}$ и Ва несколько выше. Такое распределение элементов, увеличение дисперсии и отношения Ва: $\mathrm{Sr}$ с одновременным повышением содержания Ва и уменьшением $\mathrm{Sr}$ в мигматизированных разновидностях графитсодержащих гнейсов позволяет предполагать, что мигматизация происходила с привносом щелочно-кислого материала из более глубоких зон гранитизации или из других источников и вызывала уменьшение или увеличение содержаний и перераспределение элементов. Вероятность такого предположения подтверждается также различиями в содержаниях микроэлементов в пирротине первой и второй генераций (табл. 1). Увеличение отношения $\mathrm{Ni}$ : Co в пирротине второй генерации в скважине Ф-110 указывает, по-видимому, на тот факт, что образование сульфидов шло путем метаморфогенной перекристаллизации и перераспределения сульфидов первой генерации при более высоких температурах, в результате чего $\mathrm{Ni}$ сконцентрировался в пирротине (Цамбел, и др., 1971). Метаморфической перекристаллизацией и перераспределением объясняется, видимо, также образование редких включений пентландита в пирротине второй генерации и крайне неравномерное содержание халькопирита, сфалерита и других сульфидов в породе. Вполне вероятно, что образование кристаллов молибденита связано также с метаморфической перекристаллизацией и перераспределением рудного вещества. 
Наиболее контрастные аномалии $\mathrm{Ni}, \mathrm{Cu}, \mathrm{Pb}, \mathrm{Zn}, \mathrm{Mo}$, а нередко также $\mathrm{F}$ и $\mathrm{Au}$ сопровождают интервалы керна с прожилковым типом оруденения или отдельные участки графитсодержащих гнейсов с выеокой, явно наложенной, концентрацией сульфидов (Петерселль, 1974). Содержания элементов в отдельных пробах из этих интервалов превышают в десять и более раз фоновое содержание и хорошо соответствуют составу рудной минерализации. Эти геохимические аномалии нередко имеют сложное строение. В их пределах график распределения элементов во вмещающих породах имеет зигзагообразную форму и им свойственно зональное распределение элементов. Последнее выражается прежде всєго в изменчивости величины отношений линейной продуктивности $\mathrm{Cu}$, $\mathrm{Zn}, \mathrm{Ni}, \mathrm{Mo}, \mathrm{F}$ и других элементов, а также в зональном изменении контрастности аномалии. Обычно $\mathrm{Zn}$ образует нанболее широкие, но менее контрастные аномалии по сравнению с $\mathrm{Cu}, \mathrm{Pb}$ и Мо. Аномалии $\mathrm{F}$, хотя и контрастные, наиболее узкие и не всегда сопровождают аномалии упомянутых элементов.

Секущие прожилки сульфидов в зависимости от минералогического состава подразделяются на пиритовые и рудные (Петерселль, 1974). Анализы мономинеральных фракций показывают, что пириты из «рудных» прожилков выделяются высоким содержанием Сu, Pb, Zn и Аg, а также As и более низким отношением $\mathrm{Ni}$ : Co (табл. 1). По этим показателям пириты наиболее близки к магматогенным гидротермальным пиритам и существенно отличаются от пиритов высокометаморфогенного генезиса (Цамбел и др., 1971). Несколько отличные содержания микроэлементов наблюдаются в пирите из скважины Ф-113 (табл. 1). Они наиболее близки к содержаниям этих элементов в пирротине из прожилков той же скважины. Если учесть, что в пирите из рудных прожилков этого района установлены реликты пирротина (Петерселль, 1974), то вполне вероятно предположение об отнесении этих прожилков к высокометаморфогенным сульфидам, генетически связанным с перераспределением рудного вещества в ходе последней фазы метаморфизма и мигматизации.

При сопоставлении характера сульфидной минерализации (Петерселль, 1974), средних содержаний и ассоциаций микроэлементов в вулканогенных породах и в немигматизированных или слабомигматизированных гнейсах осадочного генезиса видно их сходство друг с другом. Эти показатели в гнейсах осадочного генезиса занимают, за редкими исключениями, промежуточное положение между характерными для более основных и более кислых разновидностей вулканогенных пород. Принимая во внимание различия в характере миграции микроэлементов в процессах осадконакопления, напрашивается вывод, что основным источником рудного вещества в первично-осадочных породах ягалаской толщи служила также вулканическая деятельность геосинклинальной стадии развития района. Принципиально к аналогичному выводу в смежных районах пришли П. Хегеманн (Vähätalo, 1953) при исследовании черных сланцев на территории Финляндии и А. А. Предовский и др. (1967) при изучении рудной минерализации в метаморфических толщах Приладожья.

В процессе метаморфизма и мигматизации, в зависимости от конкретных термодинамических условий и подвижности элементов (Чернов и др., 1970), это рудное вещество в пределах толщи перекристаллизовывалось и перераспределялось. Такой вывод подтверждается наличием пирротиновых прожилков, непосредственно связанных с перекристаллизованными сингенетическими скоплениями сульфидов и вкрапленностью сульфндов в мигматитобразующих гранитах. 
Несколько иной характер носит прожилковый тип оруденения. Непосредственная связь прожилков с сингенетической вкрапленностью или другими источниками рудного вещества не установлена. Безрудные пиритовые прожилки, которые широко распространены и с которыми не связаны или развиты крайне слабо типичные околорудные изменения, видимо, приурочены к последним стадиям метаморфизма и мигматизации. Практической ценности они не представляют.

Наибольший поисковый интерес представляют «рудные» пиритовые прожилки, иногда с реликтами пирротина. Они характеризуются высокими содержаниями сульфіндов $\mathrm{Cu}, \mathrm{Pb}$ и $\mathrm{Zn}$ и обычно сопровождаются четкими гидротермальными изменениями вмещающих пород. По количественному и качественному содержанию в них микроэлементов пириты этих прожилков наиболее близки к пиритам гидротермального генезиса.

Геологи, изучавшие генезис сульфидных месторождений и рудопроявлений на открытой части Балтийского щита, не пришли в этом вопросе к единому мнению, хотя все признают наложенный характер оруденения. В частности, П. Эскола (Eskola, 1914), В. Вяхятало (Vähätalo, 1953), П. Гейер (1967), Л. Хюваринен (Hüvärinen, 1969) связывают сульфидные месторождения генетически с синорогенными гранитоидными интрузиями, Х. Веннервирта и др. (Wennervirta и др., 1970), Л. Гриненко и др. (1971) считают сульфидные руды генетически связанными с глубинными очагами, В. Мармо и др. (Marmo и др., 1951), М. Саксела (1959), Н. Магнусон (Magnusson, 1970) — с мобилизацией рассеянного рудного вещества в ходе метаморфизма и гранитизации. На основе интерпретации имеющегося материала есть основания предполагать, что наложенная сульфидная минерализация в ягалаской толще имеет сложную природу. Она связана генетически частично с мобилизацией и перераспределением рудного вещества внутри толщи, частично с более глубокими очагами метаморфизма и консолидацией ультраметаморфических гранитоидов (Глебовицкий и др., 1973) или же с невскрытыми к настоящему времени интрузиями.

\section{Л ИТ Р РА Т У Р А}

Г е й е р П. 1967. Докембрий Швеции. В кн.: Докембрий Скандинавии. М.

Глебовицкий В. А. 1971. Проблемы эволюции метаморфических процессов в подвижных областях. Л.

ГриненкоЛ. Н., Воинков Д. М., Ручкин В. Г., Тугаринов А. И. 1971. Изотопный состав серы сульфидов серноколчеданных месторождений Kарелии и некоторые вопросы их генезнса. Геология рудных месторождений, XIII, № 2 .

КивисиллаЯ.Я., Петерселль В. Х., Пуура В. А. 1974. О методике изучения и результатах оценки рудоносности кристаллического фундамента Эстонии по геохимическим данным, Минск, ИГГ АН БССР.

Петер селль В. Х. О сульфидной минерализации в кристаллических породах ягалаской толщи. Изв. АН ЭССР, Хим, Геол, 23, № 2.

Предо вский А. А., Петров В. П., Беляев О. А. 1967. Геохимия рудных элементов метаморфических серий докембрня (на примере Северного Приладожья). Л.

Саксела М. 1959. Пронсхождение руд Оутокумпу в свете тектонометаморфической мобилизации вещества. Новости зарубежной геологин, вып, II, ОНТИ. ВСЕГЕИ.

Цам бел Б., Я ржовский И. 1971. Геохимия никеля и кобальта в пирротинах различных генетических типов. В кн.: Геология и геохимия рудных месторождений. $M$.

Чернов В. М., Инина К. А., Горьковец В. Я., Раевская М. Б. 19:0 Вулканогенные железисто-кремнистые формации Карелии. Тр. Ин-та геоло гии Карельского филиала АН СССР, вып. 5. Петрозаводск, 
Eskola P. 1914. On the petrology of the Orijärvi region in south-western Finland, Bull. Comm. Géol. Finl., No. 36.

Hüvärinen L. 1969. On the geology of the copper ore field in the Virtasalmi area, eastern Finland, Bull. Comm. Géol. Finl., No. 240.

Lonka A. 1967. Trace-elements in the Finnish Precambrian phyllites as indicators of salinity at the time of sedimentation, Bull. Comm. Géol. Finl., No. 228.

Magnusson N. 1970. The origin of the iron ores in Central Sweden and the history of their alternations, Sveriges geol. unders., No. 643.

Marmo V., Mikkola A. 1951. On sulphides of the sulphide-bearing schists of Finland, Bull. Comm. Géol. Finl., No. 156.

$\mathrm{V} a$ hätalo V. 1953. On the geology of the Outokumpu ore deposit in Finland, Bull. Comm. Géol. Finl., No. 164.

Wennervirta H., Rouhunkoski P. 1970. Lithogeochemical aspects of the Vihanti zinc ore deposit, Finland, Economic Geology, 65, No. 5.

Управление геологии

Совета Министров Эстонской ССР

Поступила в редакцию $14 / \mathrm{I} \quad 1974$

\section{PETERSELL}

\section{JÄGALA KIHTKONNA KIVIMITE SULFIIDSE MINERALISATSIOONI GEOKEEMIAST JA GENEESIST}

Jägala kihtkonna metamorfiseerunud ja migmatiseerunud settelis-vulkanogeensete kivimite mikroelementidesisaldus on lähedane klargilisele. Küllalt sageli on neis jälgitav spiliit-keratofüürformatsioonile omane elementide assotsiatsioon. Vulkanogeensete kivimite reas esineb aluselisemate erimite vahekihte 'xōrgendatud $\mathrm{Cr}, \mathrm{Co}, \mathrm{Ni}, \mathrm{Cu}$ ning hapumate erimite vahekihte kōrgendatud $\mathrm{Cu}, \mathrm{Zn}, \mathrm{Mo}$ jt. elementide sisaldusega. Tavaliselt on nendes vahekihtides jälgitav ka harv süngeneetiline sulfiidikülv. Settelise geneesiga kivimikihtide reas esinevad kõrge mikroelementide kontsentratsiooniga grafiiti ja sulfiide sisaldavad erimid (tab. 1), mis on rööbistatavad Balti kilbi mustade kiltadega.

Kontrastsemad anomaalsed $\mathrm{Co}_{-}, \mathrm{Ni}-, \mathrm{Cu}-, \mathrm{Pb}_{-}, \mathrm{Zn-}$, Mo-, F- ja Au-sisaldused on seostunud lōikuvat tüüpi sulfiidse mineralisatsiooniga. Sageli on neile anomaaliatele omane tsonaalsus.

Erinevate staadiumide pürrotiini või püriidi mikruelementidesisaldus on samuti erinev (tab. 2). Lähtudes mikroelementidesisaldusest ja jaotusest kihtkonna kivimites, pürrotiinis vôi püriidis ning sulfiidse mineralisatsiooni iseloomust, võime süngeneetilise mineralisatsiooni siduda vaadeldava ala geosünklinaalsel arenguperioodil aset leidnud vulkaanilise tegevusega, lōikuvat maagistumist aga pidada hüdrotermaalsesse tüüpi kuuluvaks.

\section{PETERSELL}

\section{ON THE GEOCHEMISTRY AND GENESIS OF THE SULPHIDE MINERALIZATION OF THE ROCKS OF THE JÄGALA FORMATION}

The content of microelements in the metamorphized and migmatized sedimentaryvolcanogenic rocks of Jägala formation is approximately of the Clarke type. The association of elements proper to the spilite-ceratophyre formation is frequently to be traced. Among the vulcanogenic rocks occur intercalations of more alkaline specimens with a heightened content of $\mathrm{Cr}, \mathrm{Co}, \mathrm{Ni}, \mathrm{Cu}$, as well as more acid ones with a heightened content of $\mathrm{Cu}, \mathrm{Zn}$. Mo, and other elements. In those intercalations, a syngenetic scarce sulphide is usually traceable. In the rocks of a sedimentary genesis occur graphiteand sulphide-containing specimens with a high concentration of microelements (Table 1), which can be compared to the black schists of the Baltic shield.

The more striking anomalous contents of $\mathrm{Co}, \mathrm{Ni}, \mathrm{Cu}, \mathrm{Pb}, \mathrm{Zn}, \mathrm{Mo}, \mathrm{F}$ and $\mathrm{Au}$ are connected with the sulphide mineralization of an intersecting type. Zonality is a feature often proper to these anomalies.

The content of microelements in pyrrotine or pyrite also fluctuates in different stages (Table 2). The amounts and distribution of microelements in the rocks, in pyrrotine and pyrite, and the character of sulphide mineralization allow us to consider the syngenetic mineralization as being connected with the volcanic activity accompanying the geosynclinal period of development of the area, whereas the intersecting mineralization is of the hydrothermal type. 